www.health.gov.au/pubhlth/publicat/document/ tobccamp_2.pdf.

10. Chapman S, Wakefield M. Tobacco control advocacy in Australia: Reflections on 30 years of progress. Health Education \& Behaviour 2001;29:274-89.

11. Chapman S, Borland R, Lal A. Has the ban on smoking in NSW restaurants worked? A comparison of restaurants in Sydney and Melbourne. Med J Aust 2001;174:512-5.
12. NSW Department of Health. NSW Health Survey 1997 and 1998 (HOIST). Sydney: NSW Department of Health, 2000. Available online at www.health.nsw.gov.au.

13. Wakefield M, Clegg-Smith K, Chapman S. Framing of news coverage about the Marlene Sharp legal judgement: A tipping point for smoke-free public places in Australia? Melbourne: VicHealth Centre for Tobacco Control., 2003.

\title{
THE DECLINE IN GUN DEATHS
}

\section{Simon Chapman}

School of Public Health

University of Sydney

On 10 June 1996, following the Port Arthur massacre on 26 April of that year, an historic agreement between Australia's state and territory governments introduced a raft of radical reforms to Australia's gun laws. This article describes the decline in gun deaths following those reforms, which had been advocated by public health, domestic violence and law reform groups during the decade previous. ${ }^{1}$

The main provisions of the gun reforms were:

- a ban on the importation, ownership, sale, resale, transfer, possession, manufacture or use of semiautomatic and pump-action shotguns and rifles;
- a compensatory 'buyback' scheme, funded by an increase in the Medicare levy, whereby gun owners would be paid the market value of prohibited guns they handed in. Over 644,000 guns were removed from the community in the buyback;

- the registration of all firearms, as part of an integrated shooter licensing scheme;

- shooter licensing, based on a requirement to prove a 'genuine' reason for owning a firearm;

- requirements that all guns be stored securely;

- nationally uniform gun laws among Australia's states and territories.

One of the main provisions of the 1996 reforms was the banning of semi-automatic and pump action shot guns, which are guns frequently used in mass killings and sieges because of their capacity to fire many rounds of

\section{FIGURE1}

NUMBERS OF FIREARM RELATED DEATHS BY INTENT, AUSTRALIA, 1979 TO 1999

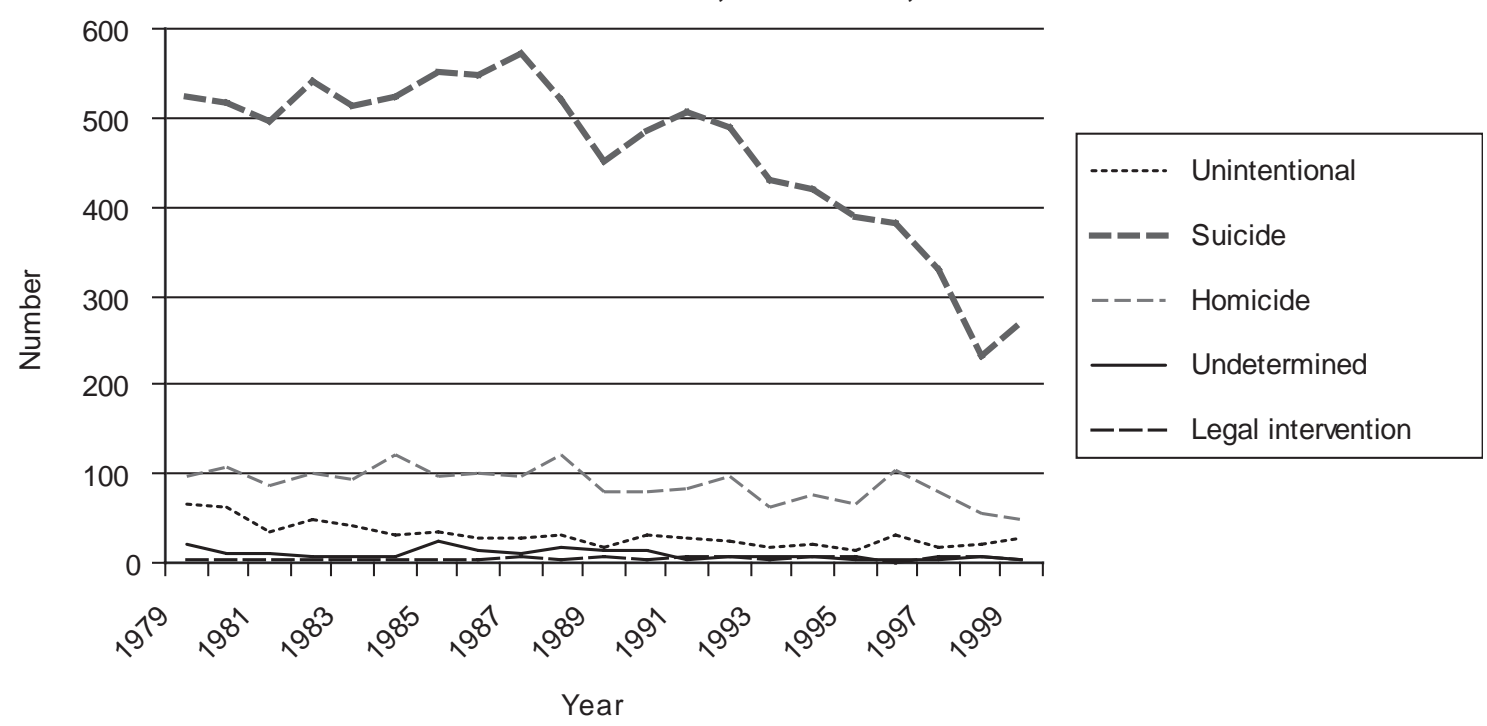

Source: Research Centre for Injury Studies, Flinders University, Adelaide. A data table for this Figure is available on online at www.nisu.flinders.edu.au/data/phonebook/queries/guns.php. 
TABLE 1

MASS KILLINGS USING FIREARMS, AUSTRALIA, 1987-2000

\begin{tabular}{|c|c|c|c|c|c|c|c|c|c|c|c|c|c|c|}
\hline Date & Location & $\mathbf{T}$ & $\mathbf{F}$ & G & V & $\mathbf{P}$ & $\mathbf{S}$ & $\mathbf{K}$ & W & Gender & A & C & M & $\mathbf{L}$ \\
\hline $28 / 04 / 96$ & Port Arthur, TAS & M & $\mathrm{N}$ & $M$ & 35 & 0 & 35 & 35 & 19 & Male & 28 & $\mathrm{~N}$ & $\mathrm{~N}$ & $\mathrm{~N}$ \\
\hline $25 / 01 / 96$ & Hillcrest, QLD & MS & $Y$ & $\mathrm{R}$ & 6 & 1 & 7 & 7 & 0 & Male & 32 & $\mathrm{~N}$ & $\mathrm{~N}$ & Y \\
\hline $31 / 03 / 93$ & Cangai, NSW & MS & $\mathrm{N}$ & $\mathrm{R}$ & 5 & 1 & 6 & 6 & 0 & Male* & 41 & $\mathrm{~N}$ & Y & $\mathrm{N}$ \\
\hline $27 / 10 / 92$ & Terrigal, NSW & $\mathrm{M}$ & $Y$ & $S$ & 6 & 0 & 6 & 6 & 1 & Male & 45 & $\mathrm{~N}$ & $\mathrm{~N}$ & $\mathrm{Y}$ \\
\hline $17 / 08 / 91$ & Strathfield, NSW & MS & $\mathrm{N}$ & $M$ & 6 & 1 & 7 & 8 & 7 & Male & 33 & $\mathrm{~N}$ & $\mathrm{~N}$ & Y \\
\hline $30 / 08 / 90$ & Surry Hills, NSW & $\mathrm{M}$ & $Y$ & $S$ & 5 & 0 & 5 & 5 & 0 & Male & 35 & $\mathrm{Y}$ & Y & $\mathrm{Y}$ \\
\hline $25 / 09 / 88$ & Oenpelli, NT & M & Y & $S$ & 6 & 0 & 6 & 6 & 0 & Male & 25 & $\mathrm{~N}$ & $\mathrm{~N}$ & $\mathrm{~N}$ \\
\hline $08 / 12 / 87$ & Queen St, VIC & MS & $\mathrm{N}$ & $M$ & 8 & 1 & 9 & 9 & 5 & Male & 22 & $\mathrm{~N}$ & Y & $\mathrm{Y}$ \\
\hline $10 / 10 / 87$ & Canley Vale, NSW & MS & $\mathrm{N}$ & $\mathrm{R}$ & 5 & 1 & 6 & 6 & 1 & Male & 23 & $\mathrm{~N}$ & $\mathrm{~N}$ & Y \\
\hline 09/08/87 & Hoddle St, VIC & $\mathrm{M}$ & $\mathrm{N}$ & M & 7 & 0 & 7 & 7 & 19 & Male & 19 & $\mathrm{~N}$ & $\mathrm{~N}$ & Y \\
\hline $19 / 06 / 87$ & Top End, NT/WA & $M$ & $\mathrm{~N}$ & $M$ & 5 & 1 & 6 & 6 & 0 & Male & 26 & Y & $\mathrm{N}$ & $\mathrm{N}$ \\
\hline Totals & & & & & 94 & 6 & 100 & 101 & 52 & & & & & \\
\hline
\end{tabular}

$\mathbf{T} \quad$ Homicide type: $\mathrm{M}=$ Murder; $\mathrm{MS}=$ Murder/Suicide

F Homicide occurred during family violence: Yes/No/Unknown

G Gun used (primary weapon): R = Rifle; $S$ = Shotgun; $M$ = Military-style semi-automatic weapon

V Victims shot dead

P Perpetrators shot dead

S Total shot dead

K Total killed by any means (one additional victim was stabbed with a knife)

W Victims wounded

A Age of perpetrator

C Perpetrator had a previous conviction for violent crime: Yes/No/Unknown

M Perpetrator had a previous history of mental illness: Yes/No/Unknown **

L Perpetrator was a licensed gun owner: Yes/No/Unknown

* These homicides were committed by two male perpetrators.

** A history of mental illness is defined as a detectable DSM-IV psychiatric illness either diagnosed, reported to authorities or even seriously suspected by others prior to the shootin-that is, minimum sufficient cause to justify legal denial of firearm possession.

Source: Alpers P. Harvard Injury Control Research Centre, Harvard School of Public Health. Boston, Massachusetts, at palpers@hsph.harvard.edu.

ammunition quickly. Since the Port Arthur gun massacre, there have been no mass shooting incidents in Australia (that is, a shooting incident in which four or more people were shot). Table 1 shows the morbidity and mortality due to mass shootings in Australia over the period June 1987 to April 1996.

Figure 1 shows changes in firearm deaths in Australia between 1979 and 1999, the latest year for which data are available. There are three main causes of firearm caused deaths in Australia: unintentional deaths (accidents), suicides, and homicides. In Australia, each of these firearmcaused deaths has declined markedly since 1977, but the rate of decline has been most dramatic since 1996 (Figure 1).

Firearm suicides have fallen by an average of 12.81 per year between 1979-1999, but by 20.33 per year in the three years since 1996. In the same period firearm homicides have fallen by 2.23 per year, but by 9.67 per year in the years since the reforms. ${ }^{2}$
Critics of gun control argue that if access to guns is made more difficult, then people intent on killing others violently will simply substitute other means such as knives or bludgeons. Similarly, they argue that someone intent on committing suicide will chose another means to do so. However, the data relating to homicide and suicide tell another story.

Homicide data comparing the period before the introduction of gun law reform in 1996 with two periods after show that Australia's homicide rate has declined from $1.94 / 100,000$ in $1989-1996,{ }^{3}$ to 1.77 per 100,000 in $1999-2000,{ }^{4}$ to $1.65 / 100,000$ in $2000-01 .^{5}$

While there has been a dramatic decline in suicide using guns, a decline that commenced in 1987 and accelerated after 1996, Australia's suicide rate has risen from 16.5/ 100,000 in 1979 to $21.2 / 100,000$ in $1999 .{ }^{6}$ However, there is no evidence available that might address the question as to whether those who took their lives by means other than firearms since 1996 had easier access to guns prior to that period and so might have otherwise used a gun. 


\section{REFERENCES}

1. Chapman S. Over our dead bodies: gun law reform after Port Arthur. Annandale, NSW: Pluto Press, 1997.

2. National Injury Surveillance Unit, Adelaide, at www.nisu.flinders.edu.au/data/phonebook/queries/guns.php.

3. Australian Institute of Criminology. Homicide in Australia, 1989-96 at www.aic.gov.au/publications/rpp/13/RPP13.pdf.
4. Australian Institute of Criminology. Homicide in Australia, 1999-00 at www.aic.gov.au/research/hmonitor/stats/ genderv.html.

5. Australian Institute of Criminology. Homicide in Australia, 2000-01 at www.aic.gov.au/publications/rpp/40/ RPP40tables.pdf.

6. Cantor C. Drop in Suicide rates for 1999 at www.aifs.org.au/ ysp/pubs/bull5cc.pdf.

\section{BUILDING THE INFRASTRUCTURE FOR PUBLIC HEALTH}

\section{Sue Morey}

Chief Health Officer (1988-1994)

NSW Department of Health

\section{Lynne Madden \\ Public Health Training and Development Branch NSW Department of Health}

'Success' in public health is facilitated by the ability to attract and retain a well-trained and enthusiastic workforce and a suitable, stable infrastructure. This article briefly describes steps taken at the end of the 1980s both to determine the need for and to create a public health infrastructure and workforce for NSW. These initiatives have contributed to the continuing development of a robust and dynamic public health community that has demonstrated its capacity to respond to a wide variety of challenges.

\section{EARLY DEVELOPMENTS OF PUBLIC HEALTH IN NSW}

By the end of the nineteenth century, all the colonies of Australia had passed public health acts following the example of Britain where the first Public Health Act was passed in 1848. In NSW, under the Public Health Act of 1896 , the profile of public health fluctuated over the years.

During the 1980s, despite the emergence of the New Public Health, ${ }^{1}$ and national initiatives to promote public health training and research, the attention given to the public health infrastructure in NSW and to the training of a public health workforce had not paralleled that directed towards the public hospital system. Public health had a low profile, and positions previously devoted to public health activities had been redirected towards the management of the public hospital system.

\section{CREATION OF AREA HEALTH SERVICES}

In 1986, area-based health services were created in metropolitan NSW by the Area Health Services Act. ${ }^{2}$ In a fundamental change, the board of directors of each area health service (AHS) was made responsible not only for the management of the acute health care facilities in their areas but also for the protection, promotion and maintenance of the health of its resident population. Previously they had no formal responsibility for the health of their resident population.

Despite these broader responsibilities, most AHSs continued to place the greatest emphasis on the management and delivery of high quality clinical services through their facilities. A Department of Public Health and Community Medicine at Westmead Hospital had by the late 1980s developed a capacity in public health research and evaluation. However this facility was unique and generally there were few health professionals with the necessary skills to plan for the health of populations.

Several developments were initiated by the NSW Department of Health around this time to change this situation. In 1988 the newly appointed Chief Health Officer made the revitalisation of the public health infrastructure in NSW one of her priorities. The initial steps were the appointment of Medical Officers of Health in each area health service and rural region, and the creation of an Epidemiology Branch within the Department.

The value of effective public health action in response to acute health problems was soon demonstrated in the efficient management of outbreaks of communicable disease. Early in 1989, the Secretary of the Department invited a proposal to expand the use of epidemiology to underpin public health across the state.

Two proposals were developed. Under the first proposal, the new Epidemiology Branch would be expanded and an organisational structure inspired by that of the United States Centers for Disease Control and Prevention (CDC) adopted. This structure included units for Infectious Disease, Chronic Disease and Injury Control, 